
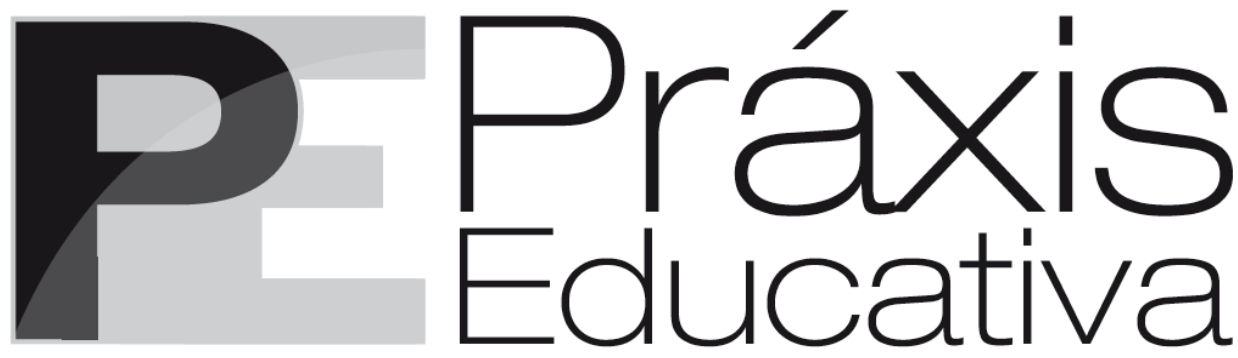

ISSN 1809-4031

elSSN 1809-4309

https://doi.org/10.5212/PraxEduc.v.15.16303.093

\title{
Educação Especial e Inclusiva em tempos de pandemia: o lugar de escola e as condições do ensino remoto emergencial*
}

\section{Special and Inclusive Education in times of pandemic: the place of school and the conditions of remote emergency education}

\section{Educación Especial e Inclusiva en tiempos de pandemia: el lugar de la escuela y las condiciones de la educación remota emergencial}

Flavia Faissal de Souza ${ }^{* *}$

https://orcid.org/0000-0003-0225-8358

Débora Dainez ${ }^{* * *}$

iD https://orcid.org/0000-0002-8223-098X

Resumo: A pandemia do coronavírus (COVID-19) traz desafios em todas as esferas da vida humana, em especial às políticas sociais. Nesse cenário, analisamos as condições de realização do ensino remoto emergencial direcionadas a um aluno com Transtorno do Espectro do Autismo, matriculado no 4o ano do Ensino Fundamental I. O estudo de caráter exploratório partiu da análise de um relato de experiência e teve como ancoragem a perspectiva histórico-cultural do desenvolvimento humano, em especial a ideia de que as condições sócio-histórico-culturais e políticas são fonte de desenvolvimento da atividade psíquica. Os

\footnotetext{
* Financiamento da Fundação de Amparo à Pesquisa do Estado do Rio de Janeiro (FAPERJ), Edital ARC-2019, Processo E-26/010.002644/2019.

** Mestrado e Doutorado em Educação pela Universidade Estadual de Campinas (UNICAMP). Docente da Faculdade de Educação da Baixada Fluminense da Universidade Estadual do Rio de Janeiro (FEBF/UERJ), do Programa de PósGraduação em Educação, Cultura e Comunicação em Periferias Urbanas (PPGECC/UERJ) e do Programa de PósGraduação em Educação (PROPEd/UERJ). Coordenadora do Laboratório Educação e Diferenças (LED/FEBF/UERJ) e do Grupo de Pesquisa em Educação, Desenvolvimento Humano e Diferenças (GEDH/UERJ). E-mail: <flaviasouza.uerj@gmail.com>.

*** Graduada em Fonoaudiologia (2006) pela Universidade Metodista de Piracicaba (UNIMEP), com Mestrado em Educação no Núcleo Práticas Educativas e Processos Interacionais do PPGE-UNIMEP (2008, Conselho Nacional de Desenvolvimento Científico e Tecnológico - CNPq). Doutorado na área Psicologia Educacional, FE-UNICAMP (2014, Fundação de Amparo à Pesquisa do Estado de São Paulo - FAPESP). Docente no Departamento de Ciências Humanas e Educação na Universidade Federal de São Carlos (UFSCar). Coordena o Núcleo de Estudos e Pesquisa em Direito à Educação - Educação Especial - UFSCar - Campus Sorocaba (NEPEDE-EES-So). E-mail: <ddainez@yahoo.com.br>.
} 
Educação Especial e Inclusiva em tempos de pandemia: o lugar de escola e as condições do ensino...

resultados evidenciam o lugar da escola na vida do aluno e apontam para o papel dessa instituição social como espaço coletivo de resistência político-pedagógica e mediadora dos processos de humanização.

Palavras-chave: Educação Especial. Ensino remoto. COVID-19.

Abstract: The coronavirus (COVID-19) pandemic poses challenges in all spheres of human life, especially in social policies. In this scenario, we analyzed the conditions for conducting emergency remote education for a $4^{\text {th }}$ grade of Elementary Education student with Autism Spectrum Disorder (ASD). The exploratory study started from the analysis of an experience report, and was anchored in the cultural-historical approach of human development, especially the idea that socio-historical, cultural, and political conditions are a source of psychic activity development. The results show the place of the school in the student's life and point to this social institution role as a collective space of political and pedagogical resistance and an institution that mediates humanization processes.

Keywords: Special Education. Remote education. COVID-19.

Resumen: La pandemia del coronavirus (COVID-19) plantea desafíos en todas las esferas de la vida humana, especialmente en las políticas sociales. En este escenario, analizamos las condiciones de realización de la educación remota emergencial dirigida a un alumno con Trastorno del Espectro del Autismo, matriculado en el 4o año de Educación Primaria I. El estudio de carácter exploratorio partió del análisis de un relato de experiencia, y fue anclado en la perspectiva histórico-cultural del desarrollo humano, en especial la idea de que las condiciones socio-histórico-culturales y políticas son fuente de desarrollo de la actividad psíquica. Los resultados muestran el lugar de la escuela en la vida del alumno y apuntan por el papel de esta institución social como espacio colectivo de resistencia político-pedagógica y mediadora de los procesos de humanización.

Palabras clave: Educación Especial. Educación remota. COVID-19.

\section{Cenário brasileiro em tempos de pandemia: o contexto das políticas sociais e da Educação Especial e Inclusiva}

Vivemos hoje a complexidade e a adversidade de uma situação inédita, marcada por um vírus, ainda pouco conhecido, que se propaga rapidamente, atingindo a população mundial e afetando com tamanha proporção a dinâmica da vida social. Encontramo-nos diante de um "ensaio sobre a cegueira" (SARAMAGO, 1995), em que se pronuncia o drama vivido pelos sujeitos e se desponta o abalo das estruturas sociais.

No Brasil, esse cenário parece ainda mais acentuado, visto que, anteriormente à eclosão da pandemia do coronavírus (COVID-19), já se anunciava um processo eminente de corrosão dos direitos sociais no interior de uma profunda crise da democracia liberal. O recuo do Estado na gestão e na sustentação do direito à vida digna já era sentido pela maioria da população brasileira que vive em situação de pobreza, com uma grave crise econômica, de emprego e de redução das políticas sociais (CARVALHO, 2020).

Ao considerarmos que a definição de políticas é inerente à base econômica, a pandemia agudiza o fato de que, em uma sociedade regida pelo neoliberalismo regulado pelo capital financeiro global, a maximização dos lucros impõe-se à vivência humana digna. A negação da crise sanitária e a ausência de políticas federais para o enfrentamento da situação, que parece ser a estratégia do atual governo, agravam a situação e os efeitos da própria pandemia, como também os processos de exclusão de direitos, as violências e as desigualdades (CHOMSKY, 2020; SANTOS, 2020a, 2020b).

Na resposta à crise humanitária, manifesta-se, ainda, o caráter seletivo das políticas públicas. Define-se, inclusive, aquele que é considerado apto a viver. Para além das desigualdades econômicas, vivenciamos outras situações de imputação de diferentes valores da vida humana. Em

Práxis Educativa, Ponta Grossa, v. 15, e2016303, p. 1-15, 2020

Disponível em: <https://www.revistas2.uepg.br/index.php/praxiseducativa $>$ 
matéria para o The New York Times, que repercutiu na mídia brasileira, Fink (2020) trata de um episódio ocorrido nos Estados Unidos, em que alguns estados regulamentaram o direito de recusa ao atendimento emergencial ou a não priorização de acesso ao respirador às pessoas com deficiência sob a alegação dessas responderem de forma mais lenta ao tratamento. O estatuto do corpo de cada pessoa passa a ser, assim, entendido como apêndice e não como dependente do corpo social, o qual, por sua vez, pode ou não demonstrar capacidade de proteger-se/defender-se dos fatores patogênicos por meio de suas instituições políticas (BIHR, 2020).

No Brasil, sob o impacto da naturalização de um "darwinismo social” (SANTOS, 2020a; LÖWY, 2020), o movimento de divulgação em massa das fake news ${ }^{1}$, que não preza pelo direito à vida e aponta para o caos social, ajudou a fragilizar as parcas estratégias para enfrentamento da COVID-19 pautadas nas recomendações sanitárias com base científica. Em meio a essas narrativas, aliadas aos preceitos políticos do governo, criou-se um falso dilema: salvar vidas ou salvar a economia, o que "[...] embasou uma resposta inadequada em ambos os campos" (CARVALHO, 2020, n.p.).

Nesse cenário político, somado às condições que se impõem em virtude do afastamento social, fator que incide nas instituições e nas formas de relação humana, apresenta-se a educação. Sob o domínio de teses liberal conservadoras, vigora, no Brasil, uma disputa antiga em prol da reforma empresarial da educação, conforme descrita por Freitas $(2014,2018)$. Nesse escopo, a qualidade da educação é alinhada aos critérios do mercado, com estrutura curricular pautada em conteúdos mínimos, avaliações padronizadas em larga escala e melhoria da escola pela via de uma gestão gerencial sustentada pelas teorias de responsabilização, de avaliações externas e do uso de tecnologias. Esse movimento preconiza a transformação dos direitos sociais, no caso a educação, em serviços ofertados pelo capital privado e/ou filantrópico.

A situação ainda é aprofundada no rol da falta de políticas, ao menos de planejamento, de curto, médio e longo prazo, e de portarias normativas para períodos de isolamento social na esfera das políticas educacionais, em especial no Governo Federal. O único parecer publicado, o Parecer CNE/CP N ${ }^{\circ}$ 5, de 28 de abril de 2020 (BRASIL, 2020), trata da realização de atividades pedagógicas não presenciais. Alinhado às experiências de outros países e aos organismos internacionais, como a Organização para Cooperação e Desenvolvimento Econômico (OCDE) (REIMERS; SCHLEICHER, 2020) e o Banco Mundial (2020), o Parecer No 5/2020 trata de apresentar diretrizes para orientar a Educação Básica e a Educação Superior durante o período de pandemia. Dentre as medidas, destaca-se a listagem de meios não presenciais que podem ser utilizados (plataformas digitais, plataformas virtuais, mídias sociais, videoaulas, vídeos educativos, programas de televisão, entre outros) e a indicação dos familiares como mediadores para as atividades escolares.

O ensino remoto emergencial anuncia-se como uma estratégia para manter o período letivo. Esse movimento expressa a tensão entre a possibilidade de intensificação da privatização da educação e a manutenção de uma certa situação de normalidade. Contudo, é preciso olhar para as condições de acontecimento dessa estratégia. Vejamos: a taxa de desemprego que se eleva no cenário da pandemia da COVID-19 (IBGE, 2020a), associada ao empobrecimento da população, agudiza os problemas de acesso às Tecnologias de Informação e Comunicação (IBGE, 2020b). Em pesquisa realizada sobre o uso da internet em casa por brasileiros em idade escolar, constatou-se

\footnotetext{
${ }^{1}$ As fake news, dais quais tratamos, compõem uma estratégia de disputa discursiva, a partir da disseminação em massa de notícias falsas, forjadas na estrutura das mídias sociais e elaboradas para captar a reação emocional das pessoas com intuito deliberado de enganar ou dar falsas percepções, nesse caso, com fins de manipulação e persuasão políticoideológica. Nessa disputa discursiva, são construídas narrativas pautadas no que é denominado de "pós-verdade" (SANTAELLA, 2018; RECUERO; GRUZD, 2019).
}

Práxis Educativa, Ponta Grossa, v. 15, e2016303, p. 1-15, 2020 Disponível em: < https://www.revistas2.uepg.br/index.php/praxiseducativa> 
Educação Especial e Inclusiva em tempos de pandemia: o lugar de escola e as condições do ensino...

que 37 milhões de crianças em idade escolar ( 9 a 17 anos), no Brasil, não tem acesso à internet em casa (CETIC, 2019a). E, ainda, há dados que apontam que cerca de 93\% das crianças de 9 a 17 anos têm acesso à internet por telefone móvel (CETIC, 2019b), o que repercute nas condições de estudo. Com isso, é possível problematizar as condições e a segurança legal do trabalho docente no contexto das aulas remotas. Em síntese, a proposição do ensino remoto emergencial, sem outras ações políticas mínimas que prezam pela manutenção da vida, da legislação do trabalho, do vínculo da criança com o espaço escolar e com o conhecimento, pode ampliar as desigualdades de direito à educação.

Ainda sobre as condições para o ensino remoto emergencial para além das condições inadequadas de ordem estrutural e de moradia, Martins, Coutinho e Corrochano (2020) apontam para outros fatores que denominam de psicopedagógicos. $O$ estudo chama atenção para o sofrimento dos alunos, que não estão habilitados para o ensino remoto e sentem falta da socialização vivenciada no âmbito escolar, e das famílias, que passam a tutoriar o ensino dos seus filhos sem ter condições adequadas para tanto. Podemos estender esse desamparo aos professores, que não têm formação suficiente para a realização do trabalho remoto.

No campo educacional, na modalidade da Educação Especial, outros desafios se apresentam, os quais são de ordem política e/ou relativos às múltiplas especificidades educacionais do alunado. Em relação às questões políticas, embora tenhamos, de certa forma, avançado no enfrentamento da privatização e da desresponsabilização histórica do Estado brasileiro como ator principal na garantia do direito à educação das pessoas com deficiência, com a Política Nacional de Educação Especial na Perspectiva da Educação Inclusiva (BRASIL, 2008); atualmente, vivemos um desfinanciamento aliado a um tensionamento para a ampliação da privatização e da filantropia no setor, que são explicitadas nas tentativas de revisão dessa política desde 2018 (BRASIL, 2018; LAPLANE; CAIADO; KASSAR, 2016; KASSAR; REBELO; OLIVEIRA, 2019).

Ainda sobre o entrelaçamento dos interesses privados nas diretrizes políticas, Souza (2016) chama atenção para um paradoxo na relação das políticas de Educação Especial com as Tecnologias Educacionais. Se, por um lado, a partir das ideias de acessibilidade e do modelo social da deficiência, as tecnologias apresentam-se como suporte às práticas pedagógicas na medida em que, em alguns casos, potencializa as relações do sujeito com o meio, ampliando as estratégias para inserção nos processos de ensino e aprendizagem; por outro, ao ser colocada como eixo central nas diretrizes políticas e prioridade de investimentos, despotencializa outras frentes imprescindíveis como a formação docente e a reorganização da estrutura e ressignificação da cultura escolar. Paira uma ideia, tanto nas diretrizes políticas educacionais como no cotidiano escolar, de que a tecnologia em si dá conta da educação das pessoas com deficiência.

Frente a esses desafios que se apresentam, propomo-nos, neste artigo, a problematizar os efeitos da pandemia da COVID-19 nos processos educacionais no campo da Educação Especial. Temos como objetivo específico analisar as condições de realização do ensino remoto emergencial direcionadas a um aluno com Transtorno do Espectro do Autismo (TEA) ${ }^{2}$ no contexto de fechamento das escolas devido às recomendações de isolamento social.

\footnotetext{
2 O Transtorno do Espectro do Autismo (TEA) é uma síndrome clínica caracterizada, segundo a Lei No 12.764, de 27 de dezembro de 2012, por: “[...] deficiência persistente e clinicamente significativa da comunicação e da interação sociais, manifestada por deficiência marcada de comunicação verbal e não verbal usada para interação social; ausência de reciprocidade social; falência em desenvolver e manter relações apropriadas ao seu nível de desenvolvimento [...]"; e "[...] padrões restritivos e repetitivos de comportamentos, interesses e atividades, manifestados por comportamentos motores ou verbais estereotipados ou por comportamentos sensoriais incomuns; excessiva aderência a rotinas e padrões de comportamento ritualizados; interesses restritos e fixos” (BRASIL, 2012, n.p.).
}

Práxis Educativa, Ponta Grossa, v. 15, e2016303, p. 1-15, 2020 Disponível em: <https://www.revistas2.uepg.br/index.php/praxiseducativa> 
Essa discussão está ancorada nos pressupostos da perspectiva histórico-cultural do desenvolvimento humano, em especial na ideia de que as condições sócio-histórico-culturais e políticas são fonte/meio de desenvolvimento que se constrói no trabalho coletivo, o que viabiliza a organização da atividade psíquica. O ensino-aprendizagem é assumido como um processo interativo, mediado e referenciado socialmente, constitutivo das funções psíquicas especificamente humanas.

\section{Deficiência, aprendizagem e desenvolvimento humano}

Encontramos na psicologia concreta, elaborada pela escola de Vigotski, conceitos e argumentos alinhados a uma orientação ética-ideológica crítica que ampliam a abordagem educacional na perspectiva do desenvolvimento humano. Ao adotar princípios de igualdade e de justiça social, essa teorização conduz uma práxis transformadora (STETSENKO, 2010, 2016, 2017), comprometida com a humanidade e com os processos de humanização. Dessa forma, a educação configura-se como prática social mediadora do desenvolvimento da atividade psíquica, sendo concebida como direito fundamental humano.

Com ancoragem no materialismo histórico-dialético, Vigotski $(1995,2000)$ assume o princípio de que o ser humano, por meio do trabalho social - que implica produção e uso de instrumentos técnico-semióticos, assim como relações entre coespecíficos - transforma a natureza em cultura e se constitui como pessoa nesse processo. A partir disso, Vigotski enuncia a "Lei geral do desenvolvimento cultural", que consiste em explicar como, no curso da história humana, as funções biológicas se transformam em funções psíquicas mediatizadas. O pressuposto que orienta o conjunto das elaborações teórico-metodológicas desse autor é, portanto, o da relação mediada do ser humano com o mundo, a qual requer a participação do outro e o trabalho com instrumentos técnico-semióticos. A mediação, concebida como um princípio teórico, permite compreender a atividade psíquica em sua relação com o contexto histórico, cultural e institucional.

Friedrich (2012), com base nas discussões vigotskianas, elabora a ideia de atividade mediatizante que consiste em elucidar como o ser humano cria artefatos e, ao mesmo tempo, sofre os seus efeitos. Isso quer dizer: se, por um lado, o indivíduo é o sujeito da ação; por outro, a ação desencadeada por ele transforma-o em objeto de sua própria ação. Para além de instrumentalizar a ação humana, os instrumentos, em suas dimensões técnica e semiótica, configuram-se em um complexo sistema de autorregulação e tornam-se um meio de constituição de novas formações psíquicas (linguagem oral e escrita, mapas conceituais, cálculo, obras de arte).

Por meio dessas reflexões, podemos conceber o ensino-aprendizagem como uma atividade mediada e mediatizante. Mediada no sentido de que o processo de apropriação do conhecimento passa pelo outro - requer, assim, a participação próxima e contínua do professor; mediatizante, uma vez que essa atividade é constitutiva das funções psíquicas complexas e emancipatórias, as quais potencializam a inserção e a participação da pessoa em práticas sociais transformadoras.

Enquanto indagava sobre as origens sociais do desenvolvimento e o papel da educação na constituição das funções psíquicas mediatizadas, Vigotski (1997) dedicou-se aos estudos sobre a questão da deficiência, área denominada na sua época como "Defectologia". Apesar de esse termo apresentar uma conotação pejorativa na atualidade, a posição do autor é revolucionária na medida em que compreende a deficiência a partir da dialética natureza e cultura, ressaltando a dinamicidade de seu conteúdo e a estrutura afetada pelos processos educacionais (DAINEZ, 2017).

Nessa linha de raciocínio, Stetsenko e Selau (2018) abordam a deficiência a partir da noção de desenvolvimento extranormativo que toma o seu curso nas práticas socioculturais. O esforço

Práxis Educativa, Ponta Grossa, v. 15, e2016303, p. 1-15, 2020 Disponível em: < https://www.revistas2.uepg.br/index.php/praxiseducativa> 
Educação Especial e Inclusiva em tempos de pandemia: o lugar de escola e as condições do ensino...

dos autores é fornecer um aporte conceitual que confronte as formas de reducionismo biológico e coloque em perspectiva o plano social do desenvolvimento. $\mathrm{O}$ argumento de extranormatividade contrapõe-se a uma visão deficitária da deficiência e centra-se na diferença dos processos de desenvolvimento, como característica do humano. Esse argumento, em vigor ainda hoje, respalda e expande a ideia do que denominamos de modelo social da deficiência.

O desenvolvimento é, então, compreendido como um processo mediado e fortemente marcado na dinâmica contextualizada das atividades cotidianas e práticas do mundo. Nesse sentido, a partir dos estudos de Vigotski, há de ter-se em vista a natureza constitutiva do meio, pois, ao mesmo tempo que se configura como fonte de desenvolvimento, pode condicionar entraves, dependendo dos fatores que operam em dada organização da sociedade (STETSENKO; SELAU, 2018; VINHA; WELCMAN, 2010).

Ao conceber o déficit como força impulsionadora de novos processos de desenvolvimento, Vigotski (1997) enfatiza as consequências sociais da deficiência. Em outros termos, ele chama atenção para o modo como o grupo social significa a deficiência, que pode gerar/intensificar obstáculos e impedimentos ou ancorar a criação de condições que sustentem novas formas de humanização (DAINEZ, 2014).

As possibilidades de desenvolvimentos estão, assim, circunstanciadas socialmente e associadas ao potencial criador da educação que se concretiza no âmbito de uma mediação pedagógica mobilizada pela diferença. A diferença, lugar da singularidade, configura-se como força motriz criadora e transformadora, capaz de tensionar a forma escolar baseada na categoria da homogeneidade.

Nas discussões vigotskianas, salienta-se, portanto, a tese de que os artefatos e os instrumentos técnicos-semióticos são inerentes ao processo transformador que emana na atividade de ensino-aprendizagem. De acordo com Kozulin e Gindis (2007), o desenvolvimento psíquico da criança com deficiência depende da qualidade da atividade de mediação pedagógica personalizada e da estrutura organizacional do ambiente de aprendizagem. A aprendizagem mediada, baseada em intervenções pedagógicas guiadas (DANIELS, 2011), configura-se pilar do desenvolvimento cultural.

Nessa direção, não cabe à educação corrigir o "defeito", mas criar mediações pautadas no enfrentamento dos processos de exclusão de direitos, que sustentem a participação ampla da pessoa com deficiência na sociedade. A escola é compreendida como um elo da criança com a vida; espaço cultural privilegiado de apropriação do conhecimento científico, de interação e de formação da cidadania, onde é possível projetar o desenvolvimento futuro.

A aprendizagem e o desenvolvimento, situados em um cenário marcado pelas desigualdades, requerem ser assumidos como dimensões fundantes de um projeto social futuro, referenciado no processo histórico a fim de sustentar a vivência humana significativa e emancipatória. Como nos chama atenção Kontopodis (2012, p.5), “[...] experienciar a coletividade pode criar condição de aprendizagem e desenvolvimento radicalmente distintas e abrir rotas de fuga para a crise neoliberal dos dias de hoje". Nesses termos, o autor fornece elementos para pensarmos na educação no contexto de crise como lócus de "desenvolvimento virtual", de uma versão de futuro articulada ao passado e ao presente, que se atualiza no processo histórico.

Práxis Educativa, Ponta Grossa, v. 15, e2016303, p. 1-15, 2020

Disponível em: <https://www.revistas2.uepg.br/index.php/praxiseducativa $>$ 


\section{Procedimentos metodológicos}

Antes de mais nada, é preciso explicitar que o artigo aqui apresentado compõe os estudos realizados no âmbito do projeto de pesquisa intitulado "O estatuto da Tecnologia Assistivas políticas e práticas de escolarização dos alunos público-alvo da Educação Especial na perspectiva da educação inclusiva", que foi submetido e aprovado pelo Comitê de Ética em Pesquisa (CEP), da Universidade do Estado do Rio de Janeiro (UERJ), Parecer n ${ }^{\circ}$ 3.960.417. Ainda, em relação aos procedimentos éticos, todos os envolvidos assinaram os Termos de Consentimento Livre e Esclarecido (TCLE), e, após as análises e a escrita deste texto, ele foi entregue aos envolvidos na situação analisada para suas observações e consentimento para publicação.

O foco deste estudo, de caráter exploratório (GIL, 2007), é a análise de um relato sobre as estratégias de ensino remoto emergencial de uma escola e de uma família para a manutenção das atividades pedagógicas com um aluno com TEA no momento que, por conta da pandemia da COVID-19, as escolas foram fechadas devido à recomendação pelas autoridades de isolamento social. O relato foi encaminhado em uma reunião remota de um grupo de pesquisa de uma universidade pública brasileira, quando a universidade havia suspendido as atividades presenciais, como um pedido de suporte à situação vivenciada por uma aluna do curso de Licenciatura em Pedagogia. Logo, o relato é situado e marcado pelo lugar de uma professora em formação, que, na situação, também é irmã de um aluno com TEA.

O relato em si já explicita o movimento da família implicado no processo de escolarização do aluno. Com ancoragem nas ideias de Bakhtin (2010), ao tratar do ato ético e responsável, assumimos que esse ato da família se desdobra na experiência em si e na sua representação. Se, por um lado, retrata aspectos de caráter objetivo; por outro, trata da "[...] singularidade irrepetível da vida que se vive" (BAKHTIN, 2010, p. 43).

Na mesma direção, Vigotski (VINHA; WELCMAN, 2010) vai tratar da vivência como a unidade da consciência, constituída de particularidades indivisíveis tanto da personalidade como do meio, sendo

[...] por um lado, de modo indivisível, o meio, aquilo que se vivencia está representado a vivência sempre se liga àquilo que está localizado fora da pessoa -e, por outro lado, está representado como eu vivencio isso, ou seja, todas as particularidades da personalidade e todas as particularidades do meio são apresentadas na vivência, tanto aquilo que é retirado do meio, todos os elementos que possuem relação com dada personalidade, como aquilo que é retirado da personalidade, todos os traços de seu caráter, traços constitutivos que possuem relação com dado acontecimento. (VINHA; WELCMAN, 2010, p. 686).

No relato, a descrição reflete, ao mesmo tempo, um contexto social mais amplo e o modo como cada sujeito envolvido foi afetado e significou as situações vividas: a professora, o aluno José e a sua família. Nesse sentido, a vivência é sempre concomitantemente coletiva e singular. Meio e sujeito interagem, constituem-se e transformam-se ao longo das relações e do tempo.

Na problemática posta entre o meio e o sujeito, Vigotski (VINHA; WELCMAN, 2010, p. 686) vai apontar que o método de pesquisa, deve dar visibilidade àquele "[...] prisma que reflete a influência do meio na criança", de onde o pesquisador "[...] deverá saber encontrar a relação existente entre a criança e o meio, a vivência da criança, isto é, de que forma ela toma consciência e concebe, de como ela se relaciona afetivamente para com certo acontecimento". Aí reside o núcleo do desenvolvimento psíquico e do caráter da criança - como o sujeito vai se constituindo "[...] nos diferentes acontecimentos vivenciados de diferentes maneiras" (VINHA; WELCMAN, 2010, p. 687). Assim, a vivência (meio e sujeito) tornam-se categoria de análise, pois unifica

Práxis Educativa, Ponta Grossa, v. 15, e2016303, p. 1-15, 2020 Disponível em: < https://www.revistas2.uepg.br/index.php/praxiseducativa> 
Educação Especial e Inclusiva em tempos de pandemia: o lugar de escola e as condições do ensino...

unidades em um todo complexo, "[...] que não perdem as propriedades inerentes ao conjunto, mas que preservam, de forma prioritária, essas propriedades próprias do conjunto" (VINHA; WELCMAN, 2010, p. 686).

Isso posto, na pré-análise, em outras palavras, na compreensão da descrição do relato, tivemos como foco as condições de significação de cada sujeito, as formas como cada um significou o vivido e as particularidades dos modos de ação. Nesse exercício analítico, buscamos dar visibilidade a algumas questões que se situam no campo da Educação Especial. Nesse movimento, algumas questões nortearam o processo: Quais os sentidos da escola? O que sustenta as mediações pedagógicas? O que ancora o ensino remoto emergencial? Qual o limite das ferramentas tecnológicas quando o lugar de estudo muda e se descaracteriza?

\section{Da escola para a casa: as condições de realização do ensino remoto emergencial}

O relato traz o movimento e as ações de vários sujeitos - a professora, o aluno, a mãe, o pai e a irmã-professora - envolvidos para a realização do ensino remoto emergencial com um aluno com TEA, o José ${ }^{3}$ : criança, moradora de um município da Região da Baixada Fluminense $/ \mathrm{RJ}^{4}$, tem 9 anos, está matriculada em uma turma do $4^{\circ}$ ano do Ensino Fundamental I e tem diagnóstico de TEA. Segundo o relato da irmã-professora, José apresenta linguagem organizada, é muito inteligente, curioso e questionador. $\mathrm{O}$ aluno ainda frequenta uma instituição especializada no contraturno para atendimento educacional e terapêutico.

Importa ressaltarmos que, mesmo em um território marcado pela escassez de recursos, o próprio movimento da família em buscar suporte aponta o como esta percebe e assume o potencial de aprendizagem, investindo nas condições de escolarização de José.

\section{Das estratégias da escola}

No período de isolamento social, as estratégias adotadas pela escola para manter o contato do aluno com as atividades educacionais ocorrem de modo assíncrono; desse modo, o encontro entre o professor e o aluno no processo de ensino-aprendizado não é simultâneo (SANTOS et al., 2020). De segunda à sexta-feira, são disponibilizadas atividades, via plataforma digital, para que os familiares as desenvolvam com o aluno em casa. São realizadas postagens de videoaulas, com explicação do conteúdo, das etapas e dos procedimentos para a execução das atividades. No caso de dúvidas ou dificuldades, a família pode contatar a professora pelo aplicativo Whats $A p p$.

Essa estratégia de organização do ensino, desenhada pela escola, fragiliza os vínculos que amparam as possibilidades mais efetivas de interação e de mediação pedagógica. O foco recai no produto, no resultado da atividade em detrimento do seu processo de desenvolvimento; espaço que se configura privilegiado das intervenções pedagógicas guiadas (DANIELS, 2011). Nesse sentido, ressaltamos a importância do contato físico, dos gestos, do toque, das sensações provocadas pela presença do outro. Dito de outro modo, as aulas remotas despotencializam a dimensão afetiva-volitiva provocada/que provoca a relação do aluno com a atividade de construção

\footnotetext{
${ }^{3}$ Nome fictício.

${ }^{4}$ A região da Baixada Fluminense, parte da região metropolitana do Rio de Janeiro, é composta por 13 municípios com população estimada em aproximadamente 4 milhões de habitantes (IBGE, 2020c). É uma região marcada pela precariedade de acesso aos bens sociais e serviços públicos, e pelas desigualdades, com grandes áreas territoriais que apresentam baixo e muito baixo Índice de Desenvolvimento Humano (IDH) (PNUD, 2014). Em relação ao enfrentamento da Covid-19, segundo estudo da Fundação Perseu Abrano (2020), dentre os 30 municípios mais vulneráveis à pandemia no Brasil, cinco estão dentre os que compõem a região da Baixada Fluminense.
}

Práxis Educativa, Ponta Grossa, v. 15, e2016303, p. 1-15, 2020 Disponível em: <https://www.revistas2.uepg.br/index.php/praxiseducativa $>$ 
do conhecimento mediada pelo outro e mediatizante do desenvolvimento psíquico (VIGOTSKI, 1997).

Dos modos de significar do aluno: espaço escola, espaço casa

Não vou fazer dever nenhum porque aqui não é a escola.

Não quero faz̧er o dever porque não vai dar tempo de brincar e vou perder o desenho que está passando na televisão.

Não quero fazer o dever porque estou muito cansado. (Relato, junho de 2020).

Nos dizeres de José, sobressai o modo como ele significa os espaços, da escola e da casa. José nega-se a realizar as atividades escolares porque está em casa e não na escola. A escola é lugar de estudar, de "fazer o dever". Para isso, é preciso estar disposto. A casa é lugar de brincar, de assistir desenho, de descansar.

A criança vê-se ocupando o lugar de aluno na escola e associa o ensino a esse ambiente. Indagamos sobre o que sustenta, nessa situação, a ideia de que o ensino somente pode ser realizado no ambiente escolar. Se colocarmos o foco nas características clínicas do TEA, diríamos que é a fixação de uma rotina que José já estava habituado; se tomarmos como ponto de partida a relação da criança com o meio, a partir dos postulados de Vigotski (VINHA; WELCMAN, 2010), entenderíamos que é a situação social da criança que contingencia a vivência e o modo de significar o lugar de aluno nas condições de isolamento. Brincar, assistir à TV, descansar são atividades já estabilizadas no cotidiano familiar das crianças de modo geral, assim como a atividade de estudo no contexto escolar. $\mathrm{O}$ ensino remoto não é ainda uma prática comum na vida das crianças. Conforme relata a irmã-professora, nos momentos que o aluno se recusa a realizar as atividades escolares em casa, ele "chora, grita, fica agressivo e muito agitado". As negativas de comportamento que envolvem essa situação evidenciam a importância de uma mediação pedagógica próxima e de uma estrutura organizacional do ambiente de aprendizagem (KOZULIN; GINDIS, 2007).

Podemos destacar, ainda, a consolidação de um vínculo escolar. José percebe-se aluno na/da escola. Diante disso, refletimos como, ao mesmo tempo que o ensino remoto carrega a tendência de ampliar as desigualdades educacionais quando não se tem garantido o acesso às plataformas virtuais e às condições adequadas para o ensino e a aprendizagem na Educação Básica, deflagra-se, nessas condições, a importância da instituição escola na vida desse aluno.

\section{Das percep̧ões, estratégias e buscas da família}

Como afirmado anteriormente, há um envolvimento da família na educação de José pautado em como esta concebe a função social da educação e a potência de José para a aprendizagem e o desenvolvimento. Inicialmente, a família traçou algumas estratégias para a realização das atividades pedagógicas postadas pela escola. Antes de tudo, decidiram que, a cada dia, um membro da família auxiliaria José na execução das atividades. José não aceitou. Então, resolveram negociar com José: se ele fizesse as atividades, ele teria acesso ao celular nos fins de semana. José aceitou; contudo, só realizou as tarefas às quintas e às sextas-feiras por estar próximo ao fim de semana. Apesar dos esforços realizados pela família, José não se engaja na atividade online, a qual passa a ser desprovida de sentido quando proposta a distância da coletividade escolar e sem a condução da professora. $\mathrm{Na}$ ausência de referências que remetem à escola, o espaço casa desmobiliza o ato volitivo de estudar.

Práxis Educativa, Ponta Grossa, v. 15, e2016303, p. 1-15, 2020 Disponível em: < https://www.revistas2.uepg.br/index.php/praxiseducativa> 
Educação Especial e Inclusiva em tempos de pandemia: o lugar de escola e as condições do ensino...

Diante de episódios de tensão e de frustração, os familiares insistiram e acreditaram nas possibilidades de aprendizagem de José e buscaram auxílio. A mãe entrou em contato com a professora e a irmã compartilhou a situação com o grupo de pesquisa.

\title{
a. O potencial de mediação da professora
}

Em um momento mais crítico, frente ao choro e à recusa em fazer a atividade, a mãe ligou para a professora e pediu para que ela conversasse com José. A professora prontificou-se a conversar com a criança.

\begin{abstract}
Infelizmente, a ligação da professora só surtiu efeito durante o tempo da chamada, ela conversou com ele que realizou alguns exercícios com o auxílio remoto dela, mas, quando ela encerrou a ligação, ele desistiu de terminar as atividades. (Relato, junho de 2020).
\end{abstract}

Destacamos o potencial de mediação da professora que convoca e sustenta a atividade de estudo. Mesmo diante das limitações interativas que definem a condição de distanciamento físico, falar com a professora gera no aluno uma aproximação com a ambiência escolar, com a prática de ensino-aprendizagem, potencializa o ato volitivo de estudar. Tal situação, mesmo que em um cenário de excepcionalidade, reitera estudos (SOUZA, 2016; PLETSCH et al., 2018) que reconhecem a importância das tecnologias educacionais no suporte ao processo de ensino e de aprendizagem no campo da Educação Especial, mas centralizam a relação professor-alunoconhecimento e o papel da mediação pedagógica. Desse modo, a tecnologia - produção científica humana - viabiliza a construção de "novos" caminhos e espaços; entretanto, a capacidade de adaptar, de planejar e de estabelecer relações é humana (VIGOTSKI, 1995, 2000).

\section{b. Das estratégias pensadas no grupo de pesquisa}

Após o relato da irmã no grupo de pesquisa e análise da situação, a partir dos pressupostos vigotskianos (VIGOTSKI, 1997; VINHA; WELCMAN, 2010) sobre a relação sujeito-meio, os pesquisadores, ao buscarem estratégias e pistas que viabilizassem a significação da ambiência escolar em casa, sugeriram algumas ações: estabelecimento de uma rotina diária e semanal para o desenvolvimento das atividades, alinhada à rotina escolar, mesmo que com flexibilidade; organização de um ambiente em casa destinado para as atividades. São aspectos que não estão incorporados na cultura da nossa sociedade e que não se restringem às especificidades do TEA.

Após duas semanas, a irmã-professora retornou ao grupo de pesquisa e fez um relato sobre os efeitos da proposta. A família construiu as seguintes estratégias: a) foi estabelecida uma rotina, mesmo que flexível, com o horário para a realização das atividades escolares que acompanhava o horário que o aluno frequentava a escola; b) o pai construiu uma escrivaninha no quarto do menino para atender à necessidade de um ambiente de estudo dentro de casa; c) a irmã-professora passou a ser a responsável pela mediação pedagógica. Após a adoção dessas estratégias, José passou a tomar a iniciativa de escrever o cabeçalho, mesmo antes do horário destinado para fazer as atividades pedagógicas, com o intuito de "adiantar" a aula.

A reorganização ocorrida, no caso de José, foi ancorada pela condição de ter uma irmãprofessora implicada no processo de escolarização do aluno. A ressignificação do espaço-tempo, do meio mais imediato, mobilizou a dimensão volitiva-afetiva do sujeito na relação com a atividade mediada pelo outro. Sujeito e meio afetam-se e transformam-se, de forma a redimensionar a vivência social singular. Esse processo reflete e refrata a sustentação social da vida - argumento que perpassa a elaboração do conceito de compensação nos escritos vigotskianos (DAINEZ; SMOLKA, 2014) -, de modo a revigorar o ato volitivo associado ao desenvolvimento cultural.

Práxis Educativa, Ponta Grossa, v. 15, e2016303, p. 1-15, 2020 Disponível em: <https://www.revistas2.uepg.br/index.php/praxiseducativa $>$ 


\section{Considerações}

O fechamento das escolas fez-nos perceber a falta do convívio, dos barulhos, do contato físico, do movimento do corpo, das interações, dos processos de socialização, da participação em uma coletividade de forma mais efetiva. Nessa ausência, manifesta-se o reconhecimento do papel social dessa instituição, sobretudo a sua importância na formação humana. Na permanência do reconhecimento, a escola configura-se como espaço coletivo de resistência político-pedagógica para o enfrentamento de uma ideologia que tenta rebaixar a produção do conhecimento, particularmente no campo das ciências humanas.

A análise da situação relatada dá visibilidade ao fato de que a escola regular é espaço dos alunos público-alvo da Educação Especial. José ocupa o lugar de aluno e reclama o espaço escolar como ambiência de estudo e de inserção cultural. Aqui reiteramos que, na escola regular, o trabalho pedagógico junto aos alunos com deficiência, para além de um serviço de atendimento educacional especializado, deve objetivar o ensino.

A relação de José com a ideia de estudar em casa traz à tona contradições que permeiam as condições atuais de ensino remoto no escopo da Educação Básica. Por um lado, assumimos que o ensino remoto não equivale ao ensino presencial, seja pelas precárias condições de vida dos professores, alunos e seus familiares, de acesso, de realização das atividades no ambiente doméstico, de ajustes às especificidades e às singularidades de cada aluno, bem como pelo limite que a ferramenta tecnológica impõe sobre as formas de interação e mediação pedagógica. Esses fatores agudizam as desigualdades educacionais historicamente presentes no sistema de educacional brasileiro. Por outro lado, em exercícios de reflexões, ainda sem um distanciamento e na esperança de perspectivar projetos, tendo em vista o período de excepcionalidade, podemos considerar que as estratégias de ensino remoto podem abrir possibilidades de vislumbrar futuro. De certa forma, o ensino remoto viabiliza a presença da escola na vida dos alunos, mantém a memória da vivência presencial nesse espaço, atualizando as relações já estabelecidas. Cria um elo, mesmo que frágil, entre o aluno e a escola, o que reitera a ideia dela como instituição, por excelência, mediadora dos processos de humanização.

Experienciar coletivamente os paradoxos e as contradições históricas que se aprofundam e agudizam no contexto social brasileiro pode abrir caminhos de criação do velho-novo, de modo a atualizar o processo histórico do desenvolvimento humano. Com isso, quem sabe, mobilizaremos forças para disputar o projeto escolar como um projeto educacional e societário.

Por fim, para além do objetivo deste texto, o relato leva-nos a uma reflexão frente ao agravamento das crises vivenciadas atualmente pelos brasileiros, alavancadas por disputas discursivas pautadas, de um lado, pelas fake News, e, por outro, pelo conhecimento produzido no âmbito das pesquisas científicas. Reiteramos, a partir das palavras da irmã-aluna-professora, o papel da universidade pública socialmente referenciada, na produção e na partilha de conhecimento científico:

Essa situação em si nos mostra a importância de estreitarmos os laços em tempos dificieis e a forma como os grupos de pesquisa e discussão podem contribuir para nossa prática dentro e fora de sala de aula, sobretudo diante dos conflitos que a vida em sociedade nos impõe e as limitações que devem ser rompidas quando o assunto é a educação de alunos com deficiência. (Relato, junho de 2020).

Práxis Educativa, Ponta Grossa, v. 15, e2016303, p. 1-15, 2020

Disponível em: < https://www.revistas2.uepg.br/index.php/praxiseducativa> 
Educação Especial e Inclusiva em tempos de pandemia: o lugar de escola e as condições do ensino...

\section{Referências}

BAKHTIN, M. M. Para uma filosofia do ato responsável. São Carlos: Pedro e João Editores, 2010.

BANCO MUNDIAL. Remote learning, distance education and online learning during the COVID19 pandemic: A Resource List by the World Bank's EdTech Team. 2020. Disponível em: https://www.worldbank.org/en/topic/edutech/brief/edtech-covid-19. Acesso em: 2 jun. 2020.

BIHR, A. França: pela socialização do aparato de saúde. In: MIKE, D. et al. (orgs.). Coronavírus e a luta de classes. Teresina, Fortaleza: Terra sem Amos, 2020. p. 25-30.

BRASIL. Ministério da Educação. Política Nacional de Educação Especial na Perspectiva da Educação Inclusiva. Brasília: MEC, 2008.

BRASIL. Lei N $\mathbf{N}^{\mathrm{1}}$ 12.764, de 27 de dezembro de 2012. Institui a Política Nacional de Proteção dos Direitos da Pessoa com Transtorno do Espectro Autista; e altera o $\int 3^{\circ}$ do art. 98 da Lei $n^{\circ}$ 8.112, de 11 de dezembro de 1990. Brasília: Presidência da República, Casa Civil, Subchefia para Assuntos Jurídicos, [2012]. Disponível em: http://www.planalto.gov.br/ccivil_03/_ato20112014/2012/lei/112764.htm\#: :text=Institui $\% 20 \mathrm{a} \% 20 \mathrm{Pol} \%$ C3\%ADtica $\% 20 \mathrm{Nacional} \% 20 \mathrm{de}, 11$ \%20de\%20dezembro\%20de\%201990. Acesso em: 7 ago. 2020.

BRASIL. Ministério da Educação. Fotos do arquivo original (Slides): Apresentação PNEE - 1604-2018. MEC. Brasília: MEC, 2018.

BRASIL. Parecer CNE/CP N ${ }^{\circ}$ 5, de 28 de abril de 2020. Reorganização do Calendário Escolar e da possibilidade de cômputo de atividades não presenciais para fins de cumprimento da carga horária mínima anual, em razão da Pandemia da COVID-19. Brasília: Ministério da Educação, Conselho Nacional de Educação, Conselho Pleno [2020]. Disponível em: http:/ / portal.mec.gov.br/index.php?option $=$ com_docman\&view $=$ download\&alias $=145011$ pcp005-20\&category_slug=marco-2020-pdf\&Itemid=30192. Acesso em: 7 ago. 2020.

CARVALHO, L. Curto-circuito: o vírus e a volta do Estado. São Paulo: Todavia, 2020.

CETIC. Centro Regional de Estudos para o Desenvolvimento da Sociedade da Informação. TICs Kids online Brasil 2018: principais resultados. 2019a. Disponível em: https://cetic.br/media/analises/tic_kids_online_brasil_2018_coletiva_imprensa.pdf. Acesso em: 17 jun. 2020.

CETIC. Centro Regional de Estudos para o Desenvolvimento da Sociedade da Informação. TICs Kids online, Portal de Dados, 2019b. Disponível em: http://data.cetic.br/cetic/explore?idPesquisa=TIC_KIDS. Acesso em: 17 jun. 2020.

CHOMSKY, N. Capitalismo selvagem e a sobrevivência da humanidade. In: TOSTES, A.; MELO FILHO, H. (orgs.). Quarentena: Reflexões sobre a pandemia e depois. Bauru: Canal 6, 2020. Não paginado.

DAINEZ, D. Constituição humana, deficiência e educação: problematizando o conceito de compensação na perspectiva histórico-cultural. 2014. Tese (Doutorado em Educação) Universidade Estadual de Campinas, Campinas, 2014.

DAINEZ, D. Desenvolvimento e deficiência na perspectiva histórico-cultural: contribuições para educação especial e inclusiva. Revista de Psicología, Santiago, v. 26, n. 2, p. 1-10, 2017. DOI: http://dx.doi.org/10.5354/0719-0581.2017.47948 
DAINEZ, D.; SMOLKA, A. O conceito de compensação no diálogo de Vigotski com Adler: desenvolvimento humano, educação e deficiência. Educação e Pesquisa, São Paulo, v. 40, n. 4, p. 1093-1108, out./dez. 2014. DOI: https://doi.org/10.1590/S1517-97022014071545

DANIELS, H. Support for children and schools through cultural intervention. In: DANIELS, H.; HEDEGAARD, M. (orgs.). Vygotsky and special needs education: rethinking support for children and schools. London: Continuum, 2011. p. 153-169.

FINK, S. U.S. Civil Rights Office rejects rationing medical care based on disability, age. New York Times, 28 mar. 2020. Disponível em: https://www.nytimes.com/2020/03/28/us/ coronavirus-disabilities-rationing-ventilators-triage.html\%20-\%20U.S. Acesso em: 10 jul. 2020.

FREITAS, L. C. Os reformadores empresariais da educação e a disputa pelo controle do processo pedagógico na escola. Educação \& Sociedade, Campinas, v. 35, n. 129, p. 1085-1114, 2014. DOI: https://doi.org/10.1590/es0101-73302014143817

FREITAS, L. C. Escolas aprisionadas em uma democracia aprisionada: anotações para uma resistência propositiva. Revista HISTEDBR On-line, Campinas, v. 18, n. 4, p. 906-926, 2018. DOI: https://doi.org/10.20396/rho.v18i4.8654333

FRIEDRICH, J. Lev Vigotski: mediação, aprendizagem e desenvolvimento: uma leitura filosófica e epistemológica. Campinas: Mercado das Letras, 2012.

FUNDAÇÃO PERSEU ABRAMO. Territorial. Vulnerabilidade das cidades brasileiras ao coronavírus. Boletim de Análise da Conjuntura, ano 5, n. 45, mar./abr. 2020. Disponível em: https:// fpabramo.org.br/wp-content/uploads/2020/04/Boletim-mensal-analise-conjuntura45.pdf. Acesso em: 3 ago. 2020.

GIL, A. C. Métodos e técnicas de pesquisa social. 5. ed. São Paulo: Atlas, 2007.

IBGE. Instituto Brasileiro de Geografia e Estatística. Pandemia dificulta acesso de 28,6 milhões de pessoas ao mercado de trabalho em maio. 2020a. Disponível em: https://agenciadenoticias.ibge.gov.br/agencia-noticias/2012-agencia-de-noticias/noticias/27972pandemia-dificulta-acesso-de-28-6-milhoes-de-pessoas-ao-mercado-de-trabalho-em-maio. Acesso em: 18 jun. 2020.

IBGE. Instituto Brasileiro de Geografia e Estatística. Pesquisa Nacional por Amostra de Domicílios Contínua (PNAD). Acesso à internet e à televisão e posse de telefone móvel celular para uso pessoal 2018. 2020b. Disponível em: https://biblioteca.ibge.gov.br/visualizacao/livros/liv101705_informativo.pdf. Acesso em: 16 jun. 2020.

IBGE. Instituto Brasileiro de Geografia e Estatística. Conheça cidades e estados do Brasil. 2020c. Disponível em: https://cidades.ibge.gov.br/pesquisas. Acesso em: 3 ago. 2020.

KASSAR, M. C. M.; REBELO, A. S.; OLIVEIRA, R. T. C. Embates e disputas na política nacional de Educação Especial brasileira. Educação e Pesquisa, São Paulo, v. 45, e217170, 2019. DOI: http://dx.doi.org/10.1590/S1678-4634201945217170

KONTOPODIS, M. Neoliberalism, Pedagogy and Human Development: exploring time, mediation and collectivity in contemporary schools. New York/London: Routledge, 2012. 
Educação Especial e Inclusiva em tempos de pandemia: o lugar de escola e as condições do ensino...

KOZULIN, A.; GINDIS, B. Sociocultural theory and education of children with special needs from defectology to remedial pedagogy. In: DANIELS, H.; COLE, M.; WETSCH, J. (orgs.). The Cambridge Companion to Vygotsky. Cambridge: Cambridge University Press, 2007. p. 332-362.

LAPLANE, A. L. F.; CAIADO, K. R. M.; KASSAR, M. C. M. As relações público-privado na educação especial: tendências atuais no Brasil. Revista Teias, Rio de Janeiro, v. 17, n. 46, p. 40 55, 2016. DOI: https://doi.org/10.12957/teias.2016.25497

LÖWY, M. "Gripezinha” o neofacista Bolsonaro diante da epidemia. In: MELO FILHO, A. T. H. (org.). Quarentena: reflexões sobre a pandemia e depois. Bauru: Canal 6, 2020. p. 147-150.

MARTINS, M. F.; COUTINHO, L. C. S.; CORROCHANO, M. C. Condições e dinâmica cotidiana e educativa na RMS (Região Metropolitana de Sorocaba/SP) durante o afastamento social provocado pelo coronavírus. 2020. Relatório de Pesquisa. (Relatório técnico-científico de pesquisa do Pós-Graduação em Educação da Universidade Federal de São Carlos, campus Sorocaba, PPGEd-SO). Sorocaba: UFSCar, 2020.

PLETSCH, M. et al. Projeto Desenho Universal para a Aprendizagem: implementação e avaliação do protocolo do livro digital acessível. 2018. Relatório de Pesquisa (Relatório técnicocientífico de pesquisa apresentado à Universidade Rural do Rio de Janeiro, UFRRJ). Nova Iguaçu: UFRRJ, 2018.

PNUD. Atlas do Desenvolvimento Humano das Regiões Metropolitanas Brasileiras. Brasilia: PNUD, Ipea, FJP, 2014.

RECUERO, R.; GRUZD, A. Cascatas de Fake News Políticas: um estudo de caso no Twitter. Galaxia, São Paulo, n. 41, p. 31-47, maio/ago. 2019. DOI: http://dx.doi.org/10.1590/1982$\underline{25542019239035}$

REIMERS, F. M.; SCHLEICHER, A. A framework to guide an education response to the COVID-19 Pandemic of 2020. OECD, 2020. Disponível em: https://globaled.gse.harvard.edu/files/geii/files/framework_guide_v2.pdf. Acesso em: 10 jun. 2020.

SANTAELLA, L. A. Pós-verdade é verdadeira ou falsa?. Barueri: Estação das Letras e Cores, 2018.

SANTOS, B. de. S. A cruel pedagogia do vírus. Coimbra: Almedina, 2020a.

SANTOS, B. Brasil tiene dos problemas de salud pública: la pandemia y el presidente Jair

Bolsonaro. Pensar la Pandemia. Observatório social del coronavírus, n. 7, 2020b. Disponível em: https://www.clacso.org.ar/biblioteca_pandemia/detalle.php?id_libro=2020. Acesso em: 15 jun. 2020.

SANTOS, E. et al. Docência na cibercultura: possibilidades de usos de REA. Disponível em: https://oer.kmi.open.ac.uk/?page_id=1173. Acesso em: 10 jun. 2020.

SARAMAGO, J. Ensaios sobre a cegueira: romance. São Paulo: Companhia das Letras, 1995.

SOUZA, F. F. Das diretrizes à oferta do serviço de Atendimento Educacional Especializado em municípios da Baixada Fluminense/RJ. Comunicações, Piracicaba, v. 23, Edição Especial, p. 117 136, 2016. DOI: https://doi.org/10.15600/2238-121x/comunicacoes.v23nespp117-136 
STETSENKO, A. Teaching-learning and development as activist projects of historical becoming: expanding Vygotsky's approach to pedagogy. Pedagogies: An International Journal, v. 5, n. 1, p. 6-16, 2010. DOI: http://dx.doi.org/10.1080/15544800903406266

STETSENKO, A. Vygotsky's theory of method and philosophy of practice: implications for trans/formative methodology. Educação, Porto Alegre, v. 39, n. 4, p. 32-41, 2016. DOI: https://doi.org/10.15448/1981-2582.2016.s.24385

STETSENKO, A. The transformative mind: expanding Vygotsky's approach to development and education. New York: Cambridge University Press, 2017.

STETSENKO, A.; SELAU, B. A abordagem de Vygotsky em relação à deficiência no contexto dos debates e desafios contemporâneos: mapeando os próximos passos. Educação, Porto Alegre, v. 41, n. 3, p. 316-324, 2018. DOI: https://doi.org/10.15448/1981-2582.2018.3.32668

VIGOTSKI, L. S. Problemas del desarrollo de la psique - Obras Escogidas. V. III. Madrid: Visor Distribuciones S.A., 1995.

VIGOTSKI, L. S. Fundamentos de Defectologia - Obras Escogidas. V. V. Madrid: Visor Distribuciones, S.A., 1997.

VIGOTSKI, L. S. Manuscrito de 1929. Educação \& Sociedade, Campinas, v. 21, n. 71, p. 21 44, 2000. DOI: https://doi.org/10.1590/s0101-73302000000200002

VINHA, M. P.; WELCMAN, M. Quarta aula: a questão do meio na pedologia, Lev Semionovich Vigotski. Psicologia USP, São Paulo, v. 21, n. 4, p. 681-701, 2010. DOI: https://doi.org/10.1590/s0103-65642010000400003

Recebido em 06/07/2020

$V$ ersão corrigida recebida em 05/08/2020

Aceito em 06/08/2020

Publicado online em 10/08/2020 